Wright State University

CORE Scholar

Physics Faculty Publications

Physics

$2-1-2010$

\title{
Mobility Analysis of Highly Conducting Thin Films: Application to $\mathrm{ZnO}$
}

David C. Look

Wright State University - Main Campus, david.look@wright.edu

K. D. Leedy

D. H. Tomich

B. Bayraktaroglu

Follow this and additional works at: https://corescholar.libraries.wright.edu/physics

Part of the Physics Commons

\section{Repository Citation}

Look, D. C., Leedy, K. D., Tomich, D. H., \& Bayraktaroglu, B. (2010). Mobility Analysis of Highly Conducting Thin Films: Application to ZnO. Applied Physics Letters, 96 (6), 62102.

https://corescholar.libraries.wright.edu/physics/100

This Article is brought to you for free and open access by the Physics at CORE Scholar. It has been accepted for inclusion in Physics Faculty Publications by an authorized administrator of CORE Scholar. For more information, please contact library-corescholar@wright.edu. 


\title{
Mobility analysis of highly conducting thin films: Application to $\mathrm{ZnO}$
}

\author{
D. C. Look, ${ }^{1, a)}$ K. D. Leedy, ${ }^{2}$ D. H. Tomich, ${ }^{3}$ and B. Bayraktaroglu ${ }^{2}$ \\ ${ }^{1}$ Semiconductor Research Center, Wright State University, Dayton, Ohio 45435, USA \\ ${ }^{2}$ Sensors Directorate, Air Force Research Laboratory, Wright-Patterson Air Force Base, Ohio 45433, USA \\ ${ }^{3}$ Materials and Manufacturing Directorate, Air Force Research Laboratory, Wright-Patterson Air \\ Force Base, Ohio 45433, USA
}

(Received 8 December 2009; accepted 18 January 2010; published online 8 February 2010)

\begin{abstract}
Hall-effect measurements have been performed on a series of highly conductive thin films of Ga-doped $\mathrm{ZnO}$ grown by pulsed laser deposition and annealed in a forming-gas atmosphere $\left(5 \% \mathrm{H}_{2}\right.$ in Ar). The mobility as a function of thickness $d$ is analyzed by a simple formula involving only ionized-impurity and boundary scattering and having a single fitting parameter, the acceptor/donor concentration ratio $K=N_{\mathrm{A}} / N_{\mathrm{D}}$. For samples with $d=3-100 \mathrm{~nm}, K_{\mathrm{avg}}=0.41$, giving $N_{\mathrm{D}}=4.7$ $\times 10^{20}$ and $N_{\mathrm{A}}=1.9 \times 10^{20} \mathrm{~cm}^{-3}$. Thicker samples require a two-layer formulation due to inhomogeneous annealing. (C) 2010 American Institute of Physics. [doi:10.1063/1.3310043]
\end{abstract}

Highly conducting thin films of $\mathrm{ZnO}$ are useful in many applications, including: (1) transparent electrodes for flatpanel displays and photovoltaic cells; (2) low-emissivity windows; (3) window defrosters; (4) light-emitting diodes; (5) laser diodes; and (6) prototype materials for transparent thin-film transistors. ${ }^{1-4}$ A key figure of merit for such films is the resistivity $\rho$; however, $\rho$ depends on two more fundamental parameters, namely, mobility $\mu$, and carrier concentration $n$. Even more fundamentally, $\mu$ and $n$ depend on donor $N_{\mathrm{D}}$ and acceptor $N_{\mathrm{A}}$ concentrations, and these quantities must be determined for a complete understanding of the material. ${ }^{5,6}$ To illustrate this point, if $n=1 \times 10^{21} \mathrm{~cm}^{-3}$ and $N_{\mathrm{A}} / N_{\mathrm{D}}$ $=0.5$, both obtainable in $\mathrm{ZnO}$, then $\rho=2.2 \times 10^{-4} \Omega \mathrm{cm}$, a competitive value; however, if $N_{\mathrm{A}}$ can be reduced such that $N_{\mathrm{A}} / N_{\mathrm{D}} \approx 0$, then $\rho=7.5 \times 10^{-5} \Omega \mathrm{cm}$, a superb value. The determination of $N_{\mathrm{D}}$ and $N_{\mathrm{A}}$ in highly conductive semiconductor materials requires an analysis of mobility $\mu$, which seldom appears in the literature. Here we introduce a simple, analytical method that can be applied to determine $N_{\mathrm{D}}$ and $N_{\mathrm{A}}$ from $\mu$ and $n$. This method includes the effects of boundary scattering, which is especially important for layers thinner than about $50 \mathrm{~nm}$.

Ga-doped $\mathrm{ZnO}$ samples, spanning a thickness range of 3-283 nm, were grown by pulsed laser deposition using a 99.99\%-pure $\mathrm{ZnO}$ target containing $3 \mathrm{wt} \% \mathrm{Ga}_{2} \mathrm{O}_{3} .{ }^{7}$ The substrate was $\mathrm{Si}$, coated with a $1-\mu \mathrm{m}$-thick layer of $\mathrm{SiO}_{2}$, for electrical isolation, and the substrate temperature during growth was held at $400{ }^{\circ} \mathrm{C}$. Thicknesses were measured by spectroscopic ellipsometry. After growth, the samples were subjected to rapid thermal annealing in forming gas $\left(5 \% \mathrm{H}_{2}\right.$ in Ar) at $400{ }^{\circ} \mathrm{C}$ for $10 \mathrm{~min}$. Temperature-dependent Halleffect measurements were performed over the range 15-320 $\mathrm{K}$ with a LakeShore 7507 apparatus. Ohmic contacts were achieved by soldering small dots of indium onto the corners of $5 \mathrm{~mm} \times 5 \mathrm{~mm}$ samples. The measured carrier concentration $n$ was independent of temperature at all thicknesses, and moreover was independent of thickness $d$ up to about 110 $\mathrm{nm}$; however, for thicker samples, the measured $n$ decreased weakly with $d$. For the samples with $d \leq 110 \mathrm{~nm}, n$ had an average value of $2.8 \times 10^{20} \mathrm{~cm}^{-3}$. The mobility $\mu$, on the

${ }^{a)}$ Electronic mail: david.look@wpafb.af.mil. other hand, increased from 1 to $35 \mathrm{~cm}^{2} / \mathrm{V} \mathrm{s}$ as $d$ increased from 3-110 $\mathrm{nm}$, and then, surprisingly, decreased for $d$ $>110 \mathrm{~nm}$. Below we demonstrate excellent quantitative agreement with a model that explains this behaviour by invoking two different effects: boundary scattering at the lower thicknesses, and nonuniform $\mathrm{H}$ passivation from the forming gas (FG) at the higher thicknesses.

The mobility data at both 20 and $250 \mathrm{~K}$ are presented in Fig. 1. (At $300 \mathrm{~K}$, the values are only slightly lower than those at $250 \mathrm{~K}$, but $300 \mathrm{~K}$ data were not available for all samples.) Although here we will explicitly fit only the $20 \mathrm{~K}$ data, clearly the fitting parameters for the 250 and $300 \mathrm{~K}$ data sets would be very similar. Because of the high concentration of ionized $\mathrm{Ga}$ donors in the sample, we expect that the scattering over the whole temperature range will be dominated by charged donors and acceptors, not phonons. Furthermore, $n$ is independent of temperature so we employ the degenerate form of the Brooks-Herring formula:

$$
\begin{aligned}
\mu_{i i}(K, n) & =\frac{24 \pi^{3} \varepsilon_{0}^{2} \hbar^{3}}{Z^{2} e^{3} m^{* 2}} \frac{n}{N_{i i}} \frac{1}{\ln [1+y(n)]-\frac{\dot{y}(n)}{1+y(n)}} \\
& =\frac{146.9}{\ln \left(1+6.46 n_{20}^{1 / 3}\right)-\frac{6.46 n_{20}^{1 / 3}}{1+6.46 n_{20}^{1 / 3}}} \frac{1-K}{1+K} \frac{\mathrm{cm}^{2}}{\mathrm{~V} \mathrm{~s}},
\end{aligned}
$$

where

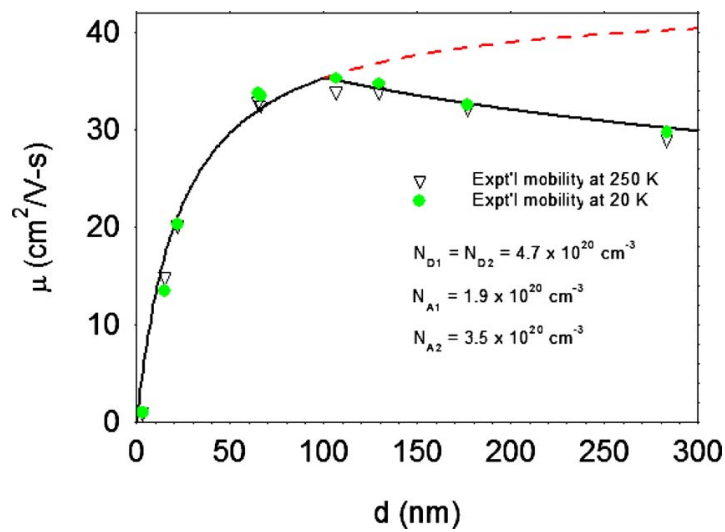

FIG. 1. (Color online) Temperature-dependent mobility as a function of film thickness for $\mathrm{ZnO}$ samples grown by pulsed laser deposition. 


$$
y(n)=\frac{3^{1 / 3} 4 \pi^{8 / 3} \varepsilon_{0} \hbar^{2} n^{1 / 3}}{e^{2} m^{*}}=6.46 n_{20}^{1 / 3} .
$$

Here the dielectric constant $\varepsilon_{0}$ and effective mass $m^{*}$ are based on relative values of 8.12 and 0.3 , respectively; also, $Z$ is the ionization charge in units of $e$, assumed to be unity for both donors and acceptors. Finally, the concentration of ionized centers $N_{i i}$ is given by $N_{i i}=N_{\mathrm{D}}+N_{\mathrm{A}}=2 N_{\mathrm{A}}+n$, and $K$ $=N_{\mathrm{A}} / N_{\mathrm{D}}$, the compensation ratio. On the right-hand side of Eq. (1), we have written $\mu_{i i}$ in a convenient form for calculation, where $n_{20}$ is a normalized value of $n$ such that $n$ $=n_{20} \times 10^{20} \mathrm{~cm}^{-3}$. It is illustrative to write Eq. (1) as:

$$
\mu_{i i}(K, n)=\mu_{\max }(n) \frac{1-K}{1+K},
$$

where

$$
\mu_{\max }(n)=\frac{146.9}{\ln \left(1+6.46 n_{20}^{1 / 3}\right)-\frac{6.46 n_{20}^{1 / 3}}{1+6.46 n_{20}^{1 / 3}}} .
$$

Note that the denominator of Eq. (1) is slowly varying with $n$ and moreover is approximately unity for $n=1 \times 10^{20} \mathrm{~cm}^{-3}$. For our average value of $n, 2.8 \times 10^{20} \mathrm{~cm}^{-3}, \mu_{\max }$ $=104 \mathrm{~cm}^{2} / \mathrm{V} \mathrm{s}$. This would be the mobility if $K \sim 0$, and is much higher than the value $43 \mathrm{~cm}^{2} / \mathrm{V} \mathrm{s}$, which obtains at our experimental value of $K, 0.41$ (see below). This comparison shows the desirability of reducing the acceptor concentration $N_{\mathrm{A}}$, which raises both the concentration and mobility. Increasing $N_{\mathrm{D}}$, on the other hand, raises concentration but reduces mobility.

Clearly, $\mu_{i i}$ given by Eq. (1) cannot by itself explain the data of Fig. 1, because Eq. (1) is independent of $d$. To address this problem, we consider the potential effects of boundary scattering. The electrons in a layer of thickness $d$ may lie at a distance anywhere between 0 and $d / 2$ from a boundary, either the surface or interface. Thus, the average distance from one of these boundaries is $d / 4$, and we could roughly define a boundary scattering time for degenerate electrons by $\tau_{\text {bdry }}(n)=(d / 4) / v_{\mathrm{Fermi}}(n)$, where $v_{\mathrm{Fermi}}(n)$ is the temperature-independent Fermi velocity. This formulation is of course completely phenomenological and ignores details of the scattering process, such as variations in $d$ that produce the scattering itself, and directional averaging of the electron momentum. It also ignores quantum effects, which must become important for $d$ approaching the electron de Broglie wavelength, about $3 \mathrm{~nm}$ at $n=2.8 \times 10^{20} \mathrm{~cm}^{-3}$. In spite of these shortcomings, the effective distance parameter $d / 4$ turns out to be a reasonable average mean free path for our particular set of samples. Then, since the mobility associated with $\tau_{\text {bdry }}$ is $\mu_{\text {bdry }}=\left(e / m^{*}\right) \tau_{\text {bdry }}$, we get the empirical formula,

$$
\mu_{\mathrm{bdry}}(d, n)=\frac{e}{m^{*}} \frac{d / 4}{v_{\mathrm{Fermi}}(n)}=\frac{e}{\hbar} \frac{d / 4}{\left(3 \pi^{2} n\right)^{1 / 3}}=2.645 \frac{d_{\mathrm{nm}}}{n_{20}^{1 / 3}} \frac{\mathrm{cm}^{2}}{\mathrm{~V} \mathrm{~s}},
$$

where, again for convenience, we have expressed $d$ in nanometers. Note that Eq. (5) is independent of any material parameters, and thus is quite universal. Note also that it is only weakly dependent upon $n$ and in fact varies less than a factor five over the range $n=1 \times 10^{19}-1 \times 10^{21} \mathrm{~cm}^{-3}$. For our conditions (average $n_{20} \approx 2.8$ ), a 5 -nm-thick sample would have a mobility limited to $9 \mathrm{~cm}^{2} / \mathrm{V} \mathrm{s}$ from boundary scattering alone. To now get the total mobility, involving both scattering mechanisms, we can apply Matthiessen's rule, since our electrons are degenerate ${ }^{5}$

$$
\mu(d, n, K)=\left[\mu_{i i}(K, n)^{-1}+\mu_{\text {bdry }}(d, n)^{-1}\right]^{-1} .
$$

For the convenient determination of $N_{\mathrm{D}}$ and $N_{\mathrm{A}}$, we define a dimensionless quantity $Q=\mu_{\max }\left(n_{\text {expt }}\right)\left[\mu_{\text {expt }}^{-1}-n_{\text {expt }}^{1 / 3} /\right.$ $\left.2.645 d_{\text {expt }}\right]$, and then $K=(Q-1) /(Q+1)$, and finally $N_{\mathrm{D}}$ $=n_{\text {expt }} /(1-K)$ and $N_{\mathrm{A}}=n_{\text {expt }} K /(1-K)$, where $n_{\text {expt }}$ is in units of $10^{20} \mathrm{~cm}^{-3}$ and $d$ in nanometers, as before. For the six samples with $d \leq 110 \mathrm{~nm}$ in Fig. 1, the average $n_{20}=2.8$, and an excellent fit to the data is found for $K=0.41$. Then, from the above equations, $N_{\mathrm{D}}=4.7 \times 10^{20} \mathrm{~cm}^{-3}$ and $N_{\mathrm{A}}=1.9$ $\times 10^{20} \mathrm{~cm}^{-3}$.

Thus, Eq. (6) provides a good description of $\mu$ versus $d$ for $d \leq 110 \mathrm{~nm}$. For $d>110 \mathrm{~nm}$, however, Eq. (6) is clearly not adequate. We hypothesize that the reason involves an incomplete annealing of layers thicker than about $100 \mathrm{~nm}$. Forming gas contains $\mathrm{H}$, and isolated $\mathrm{H}$ atoms are known to move rather easily in $\mathrm{ZnO}^{8-14}$ In fact, even the most stable member of this class, substitutional $\mathrm{H}_{\mathrm{O}}$, is believed to completely diffuse out of the sample for temperatures higher than about $475{ }^{\circ} \mathrm{C} .{ }^{12} \mathrm{H}$ can also attain stability by forming complexes with certain impurities and defects, ${ }^{13}$ such as the $\mathrm{Zn}$ vacancy $V_{\mathrm{Zn}},{ }^{8,13} \mathrm{Cu},{ }^{8}$ and $\mathrm{N} .{ }^{14}$ For example, the neutral complex $V_{\mathrm{Zn}} \mathrm{H}_{2}$ is stable to about $400{ }^{\circ} \mathrm{C}^{8}$. Before the $\mathrm{FG}$ anneal, the dominant acceptors in our samples are likely $V_{\mathrm{Zn}}$ and/or $\mathrm{Ga}_{\mathrm{Zn}}-V_{\mathrm{Zn}}$, because $V_{\mathrm{Zn}}$ has a low formation energy in $n$-type $\mathrm{ZnO}$ (Ref. 15) and also because there is no evidence of impurities other than $\mathrm{Ga}$ with concentrations $>10^{20} \mathrm{~cm}^{-3}$. Indeed, $V_{\mathrm{Zn}}$ has been directly identified as the dominant acceptor in certain types of $\mathrm{ZnO}{ }^{16}$ We propose that the $\mathrm{H}$ present in the forming gas passivates $V_{\mathrm{Zn}}$ and $\mathrm{Ga}_{\mathrm{Zn}}-V_{\mathrm{Zn}}$ acceptors, forming neutral complexes. However, this process takes time, and perhaps our annealing conditions $(10 \mathrm{~min}$ at $400{ }^{\circ} \mathrm{C}$ ) lead to an $\mathrm{H}$ saturation in only the top $100 \mathrm{~nm}$, or less. Besides passivating acceptors, $\mathrm{H}$ can also create relatively stable, shallow donors, in particular $\mathrm{H}_{\mathrm{O}},{ }^{17}$ mentioned above. This process, too, can be depth dependent if the $\mathrm{H}$ diffusion does not extend throughout the whole layer.

To model depth-dependent diffusion we must add a second layer, of thickness $d_{2}$, carrier concentration $n_{2}$, and compensation ratio $K_{2}$. In this case we do not know $n_{2}$ beforehand, because we cannot easily perform a separate Halleffect measurement on the second layer. Thus, we have two new fitting parameters, $n_{2}$ and $K_{2}$, or equivalently $N_{\mathrm{D} 2}$ and $N_{\mathrm{A} 2}$, since $K_{2}=N_{\mathrm{A} 2} / N_{\mathrm{D} 2}$ and $n_{2}=N_{\mathrm{D}_{2}}-N_{\mathrm{A} 2}$. The mobility in this two-layer system then becomes,

$$
\begin{aligned}
& \mu_{2-\text { layer }}\left(d_{1}, d_{2}, n_{1}, n_{2}, K_{1}, K_{2}\right) \\
& \quad=\frac{\mu\left(d_{1}, n_{1}, K_{1}\right)^{2} n_{1} d_{1}+\mu\left(d_{2}, n_{2}, K_{2}\right)^{2} n_{2} d_{2}}{\mu\left(d_{1}, n_{1}, K_{1}\right) n_{1} d_{1}+\mu\left(d_{2}, n_{2}, K_{2}\right) n_{2} d_{2}} .
\end{aligned}
$$

Applying this formula to the data of Fig. 1 produces a good fit to the three samples having thicknesses $d>110 \mathrm{~nm}$, with the following fitting parameters: $N_{\mathrm{D} 2}=4.7 \times 10^{20} \mathrm{~cm}^{-3}$ and $N_{\mathrm{A} 2}=3.5 \times 10^{20} \mathrm{~cm}^{-3}$, along with the previous parameters, $N_{\mathrm{D} 1}=4.7 \times 10^{20} \mathrm{~cm}^{-3}$ and $N_{\mathrm{A} 1}=1.9 \times 10^{20} \mathrm{~cm}^{-3}$. For this fit, we have purposely set $N_{\mathrm{D} 2}=N_{\mathrm{D} 1}$, because the presence of $\mathrm{H}$ should not affect the $\mathrm{Ga}_{\mathrm{Zn}}$ donors, since both are positively charged. These parameters produce a good fit over the full thickness range and are consistent with the following conclusions: (1) in the top $100 \mathrm{~nm}$ or so, the $\mathrm{H}$ atoms from the 
forming gas passivate about half of the acceptors, thought to be $V_{\mathrm{Zn}}$ and $\mathrm{Ga}_{\mathrm{Zn}}-V_{\mathrm{Zn}}$ centers; and (2) there is no strong evidence for new shallow donors, such as $\mathrm{H}_{\mathrm{O}}$. However, it should be cautioned that, although the assumed acceptor ionic charge $Z_{\mathrm{A}}=1$ is valid for $\mathrm{Ga}_{\mathrm{Zn}}-V_{\mathrm{Zn}}$, it is not necessarily valid for isolated $V_{\mathrm{Zn}}$, which could have $Z_{\mathrm{A}}=2$. If the latter case, we must set $n=N_{\mathrm{D}}-2 N_{\mathrm{A}}$ and $N_{\text {ii,eff }}=N_{\mathrm{D}}+4 N_{\mathrm{A}}$ in Eq. (1), and then the fitted values of $N_{\mathrm{D}}$ and $N_{\mathrm{A}}$ would be somewhat different. (For layer $1, N_{\mathrm{D} 1}$ and $N_{\mathrm{A} 1}$ would be 4.1 $\times 10^{20}$ and $0.63 \times 10^{20} \mathrm{~cm}^{-3}$, instead of $4.7 \times 10^{20}$ and 3.5 $\times 10^{20} \mathrm{~cm}^{-3}$, respectively.) In this regard, it is interesting to compare the calculated $N_{\mathrm{D}}$ with the expected concentration of $\mathrm{Ga}$ atoms in the $3 \mathrm{wt} \% \mathrm{Ga}_{2} \mathrm{O}_{3}$ target. If we assume that (1) each $\mathrm{Ga}_{2} \mathrm{O}_{3}$ molecule entering the growing $\mathrm{ZnO}$ crystal supplies two Ga atoms and two $\mathrm{O}$ atoms to the lattice, (2) the third $\mathrm{O}$ atom leaves in gaseous form, and (3) the final $\mathrm{ZnO}$ crystal has the density of bulk $\mathrm{ZnO}$, then the expected maximum density of Ga atoms would be

$$
[\mathrm{Ga}]=\frac{\frac{\rho_{\mathrm{ZnO}} N_{0}}{M_{\mathrm{ZnO}}}}{1+\frac{1-x}{2 x} \frac{M_{\mathrm{Ga}_{2} \mathrm{O}_{3}}}{M_{\mathrm{ZnO}}}},
$$

where $\rho_{\mathrm{ZnO}}$ is the $\mathrm{ZnO}$ density $\left(5.61 \mathrm{gm} / \mathrm{cm}^{3}\right) ; M$, the molecular weight; $x$, the fractional weight of $\mathrm{Ga}_{2} \mathrm{O}_{3}(0.03$ in this case); and $N_{0}$, Avogadro's number (6.022 $\times 10^{23}$ molecules/mole). Equation (8) yields $[\mathrm{Ga}]=1.085$ $\times 10^{21} \mathrm{~cm}^{-3}$, so that $N_{\mathrm{D} 1}=N_{\mathrm{D} 2}=4.7 \times 10^{20}$ is about $43 \%$ of this value, a reasonable doping efficiency. There are several possibilities for the other $57 \%$ of the Ga atoms, including $\mathrm{Ga}_{\mathrm{Zn}}-V_{\mathrm{Zn}}$ acceptors, as mentioned above. In any case, the determination of $N_{\mathrm{D}}$ and $N_{\mathrm{A}}$ by the method presented here allows these issues to be studied quantitatively.

In summary, we have developed a simple analytical model to explain the thickness dependence of mobility in degenerate semiconductor thin films, and have applied it to $\mathrm{ZnO}$ layers grown by pulsed laser deposition to thicknesses of 3-280 nm. The theoretical fits give good values of the donor and acceptor concentrations and show that the efficiency of $\mathrm{Ga}$ donor doping from the $\mathrm{Ga}_{2} \mathrm{O}_{3}$ target is about $43 \%$ under our growth and annealing conditions. However, in films thicker than about $100 \mathrm{~nm}$, the average carrier concentration and mobility are somewhat reduced due to less effective H-related passivation of acceptors in the lower parts of the films.

We wish to thank T.A. Cooper for the Hall-effect measurements and B. Claflin for helpful discussions. Support is gratefully acknowledged from the following sources: AFOSR Grant No. FA9550-07-1-0013 (K. Reinhardt), NSF Grant No. DMR0513968 (L. Hess), and DOE Grant No. DEFG02-07ER46389 (R. Kortan).

${ }^{1}$ T. Minami, Semicond. Sci. Technol. 20, S35 (2005).

${ }^{2}$ D. C. Look, Mater. Sci. Eng., B 80, 383 (2001).

${ }^{3}$ S. J. Pearton, D. P. Norton, K. Ip, Y. W. Heo, and T. Steiner, Prog. Mater. Sci. 50, 293 (2005).

${ }^{4}$ U. Ozgür, Y. I. Alivov, C. Liu, A. Teke, M. A. Reshchikov, S. Dogan, V. Avrutin, S. J. Cho, and H. Morkoc, J. Appl. Phys. 98, 041301 (2005).

${ }^{5}$ D. C. Look, Electrical Characterization of GaAs Materials and Devices (Wiley, New York, 1989).

${ }^{6}$ D. C. Look, J. Appl. Phys. 104, 063718 (2008).

${ }^{7}$ B. Bayraktaroglu, K. Leedy, and R. Bedford, Appl. Phys. Lett. 93, 022104 (2008).

${ }^{8}$ E. V. Lavrov, J. Weber, F. Börrnert, C. G. Van de Walle, and R. Helbig, Phys. Rev. B 66, 165205 (2002).

${ }^{9}$ G. A. Shi, M. Stavola, S. J. Pearton, M. Thieme, E. V. Lavrov, and J. Weber, Phys. Rev. B 72, 195211 (2005).

${ }^{10}$ M. G. Wardle, J. P. Goss, and P. R. Briddon, Phys. Rev. Lett. 96, 205504 (2006).

${ }^{11}$ N. H. Nickel, Phys. Rev. B 73, 195204 (2006).

${ }^{12}$ J. Bang and K. J. Chang, J. Korean Phys. Soc. 55, 98 (2009).

${ }^{13}$ E. V. Monakhov, A. Yu. Kuznetsov, and B. G. Svensson, J. Phys. D 42, 153001 (2009)

${ }^{14}$ S. J. Jokela and M. D. McCluskey, Phys. Rev. B 76, 193201 (2007).

${ }^{15}$ A. Janotti and C. G. Van de Walle, Phys. Rev. B 76, 165202 (2007).

${ }^{16}$ F. Tuomisto, V. Ranki, K. Saarinen, and D. C. Look, Phys. Rev. Lett. 91, 205502 (2003).

${ }^{17}$ A. Janotti and C. G. Van de Walle, Nature Mater. 6, 44 (2007).

${ }^{18}$ D. C. Look and R. J. Molnar, Appl. Phys. Lett. 70, 3377 (1997). 